pulse, 140 ; temperature, IO2 degs. On the eighteenth, the abdomen was again distended, and, though discharges of fluid fæces went on during the day, not a particle of air was suffered to escape. The next five days were spent without change; the tension again became frightful, and the sufferings during these weary days were very great, Sometimes the peristalsis was allowed to have its full swing ; generally it was kept within bounds by opium or belladonna, and a light poultice over the abdomen gave much relief. On the night of the twenty.fourth, chloroform was carefully given, and the colon was again punctured. The cannula was passed well downwards, and then held against the abdominal wall to prevent its slipping, as it had done before. It was retained for some time; much gas escaped, and, as the peristalsis came and went, there were great discharges. The tension was immensely relieved; opium was again injected, and, as before, she slept all through the night.

During the next day, and the day after, she was feeble, scarcely able to speak. The pulse had fallen to 120 ; the bowels had been moved freely by oil, and, soon after, flatus passed in great quantity. Preceding this improvement, there was a profuse diuresis, sixty ounces of urine having been passed within twelve hours. On the twenty-ninth day, the belly was quite flat ; there was no return of distension, and, though reduced nearly to a skeleton, she rapidly gained flesh. Seven weeks after the operation, she returned to Ireland, and remains well.

There can be little doubt that the puncture of the intestine saved this patient. It did so by gaining time ; for, as already stated, it was pretty certain that a portion of the adherent bowel, which formed the roof of the hæmatocele, had become trapped as it fell downwards after evacuation of the fluid. It was hoped, if the patient could only live long enough, that more or less absorption of the connecting lymph would soon take place, and lead to some change of position in the arrangement of the part at fault, that would allow of air to pass along with the solid contents. Fortunately, this happened. The profuse diuresis, which occurred just before the relief, I have seen take place once before in a case of obstruction, which terminated favourably.

I do not guess at the source of hæmorrhage in this case. Some might, perhaps, blame the cautery, or the slipping of some of the catgut ligatures ; but there have been similar cases of hrematocele after ovariotomy in which the clamp was used, and in which no adhesions existed.

I have never seen any harm in puncturing hæmatoceles or collections of fluid in the pelvis by the rectum. If, on the occurrence of tension, I wish to empty Douglas's space, I prefer to do so by the rectum rather than by the vagina. With a proper instrument, this is a safe procedure. What I have long used for this purpose is the ordinary trocar and cannula, of the size and length of a No. 6 catheter. The shoulder of the cannula is moved an inch forwards from the end, so as to allow of a long India-rubber tube being slipped on as the trocar is withdrawn. With the slightest attention, no air can thus enter. The operation can be repeated as often as necessary, and, if the fluid is too thick, it can be sucked out with a syringe. Of course, I would not drain by the rectum ; but drainage by the vagina is a very imperfect way of keeping Douglas's space free. With a patient on her back, and a dilated rectovaginal pouch, a tube passing through the vagina will not keep Douglas's space empty, but will leave ample room for the stagnation of fluids, which can hardly help becoming putrid. It seems to me, therefore, that Dr. Marion Sims's scheme for the drainage of the abdomen by the vagina, in all cases of ovariotomy, will not satisfactorily accomplish his object. Even if it did, it would almost always be unnecessary, and it might, by carrying putridity inwards, not seldom lead to bloodpoisoning of the patients.

\section{THERAPEUTIC MEMORANDA.}

\section{ONYCHIA MALIGNA.}

I was much interested in perusing Mr. Mac Cormac's remarks on this distressing malady, and having met with many cases of this and the allied disease "ingrowing nail," I was delighted to find what I considered, and experience has proved, a perfect cure. Rest and attention to the state of general health having preceded, the fungous growth is then burnt with strong nitric acid, washed with water, and poulticed. The relief is certain, and the repetition of the application seldom necessary. If there should be any trouble with the nail, the tender flesh may be protected by the insertion of a thin piece of compressed sponge, kept in its place by strips of plaster applied longitudinally to avoid compression.

BENJAMIN BLOWER, Liverpool.

\section{CLINICAL LECTURE}

\section{O N V E R E N T SQ U I N T .}

BY R. LIEBREICH,

Ophthalmic Surgeon and Lecturer, St. Thomas s Hospital.

I sHow you to-day three patients with strabismus convergens, who represent three forms of strabismus, different with regard to treatment. In the first case, the squint shows itself only while the look is attentively fixed upon an object, whether near or remote. If, however, the patient look absently before him, contenting himself with an undefined image of the object, his eyes remain perfectly straight. This state is characteristic of the first stage of the ordinary strabismus convergens based on hypermetropia. In order to see distinctly with eyes the refraction of which is not sufficiently strong, it is necessary to make a great effort of accommodation. There is a connection between the accommodation of each eye-that is, of the power of the eye to adapt itself to different distances-and between the muscles which make the two eyes converge to a single point. On account of this connection, a hypermetropic eye can only make the effort of accommodation necessary to correct its fault of refraction, by making at the same time a very great effort of the two recti interni--that is, by producing too high a degree of convergency, which, in fact, constitutes the strabismus. So the periodical squint becomes a means by which hypermetropical children succeed in seeing distinctly. It is true that, by doing so, they give up the binocular vision; but they see better with one eye sharply fixed than with both eyes incompletely adapted to the distance of the object. If, in these cases, the optical fault of the eyes be corrected by adding glasses which make the vision equal to that of a normal eye, the squint will disappear; for then every distance requires only the normal quantity of effort of accommodation, as well as the normal degree of convergency. The first indication of treatment is to find out the degree of hypermetropia and of the astigmatismus which may be combined with it, and to advise the use of spectacles which correct these optical faults. This is not always easy. The principal difficulties we meet with are the following.

I. The youth of the patient. There are cases where the affection begins as early as the second year, and even earlier, at a time when the use of spectacles is out of the question. In such cases, one must be content to draw the attention of the parents to the matter, in order as far as possible to prevent the child irom fixing his eyes on small near objects; and, later, reading must not be attempted without the use of the right spectacles.

2. A difficulty based on spasm of accommodation. In order to ascertain the refraction of an eye-that is, to find out which is the farthest point to which it can accommodate itself-it is necessary to suspend the accommodation. It is, however, not always possible to obtain this in eyes which, on account of hypermetrophy, are in a constant state of tension of the accommodation. On being examined, they either appear not at all hypermetropical, or at least not so much as they really are. Their hypermetropia is then called latent. In order to make it manifest, different ways may be adopted : either the accommodation may be entirely suspended by the instilling of atropine, and then the refraction is easily ascertained; or, choosing a slower way, we may diminish by degrees the effort of accommodation by the use of convex spectacles. These spectacles are to be chosen first approximativehy; then gradually stronger ones must be used, until they are in accordance with the degree of hypermetropia.

3. A third difficulty will often be found in the strong aversion of parents to seeing their children wear spectacles. They often urge to have an immediate operation performed, in order that the deformity of squinting may be removed at once. Some surgeons give way to such wishes; but let me earnestly caution you against this. The result of an operation in such a case is, that the convergent squint is, in the most favourable case, removed; that is, during the fixation, under the conditions which produced the convergence before, the axes of the eye are now more or less well adapted. On the contrary, while the look is not definitely fixed on an object-that is, under the conditions which, befo:e the operation, made the axes of the eyes stand more or less parallel 
-there is now a divergent squint produced. If now you were to attempt to correct this divergent squint by a tenotomy of the rectus externus, the movement of both eyes would become irregular in every direction; and the final result of such untimely surgical interference you would find to be this : irregularity of the movement and restriction of mobility; too strong prominence and difference in the size; and, lastly, amblyopia of the eye operated upon. If we compare with this the perfect correction of this position, the conservation of the sight, and its power of endurance, which are obtained by a timely and constant use of the right spectacles, we must come to the conclusion that, wherever the convergent squint is purely periodical, no operation should be performed.

It is quite otherwise with that category of squint which is represented by the second case introduced to your notice. Here we find a permanent deviation of the axis of the eye, but in a different degree, according to the effort of accommodation. During the fixation the degree of the convergency increases, and in such cases the necessity of an operation is indicated ; but care must be taken not to produce so strong an effect, that, even during the fixation, there will be no deviation at all ; for, by so doing, we should cause divergency during the vague look which we mentioned before. The operation is only intended to correct the constant deviation. That deviation which shows itself during the fixation can only be rectified by the spectacles which correct hypermetropia.

The third case shows a constant and very high state of convergency, which must be corrected as far as possible by operation. How can this be best performed?

If the internal rectus muscle be divided in the ordinary way, it is possible to correct a squint of from two to two and a half lines in adults, and from two and a half to three lines in children. But, if the deviation exceed this extent, it will be necessary to perform two, three, or even more, successive operations.

Whilst the division of the effect between the two operations, one on each eye, offers certain advantages with regard to the symmetry and uniformity of the movements of the eyes, the performance of a third or fourth operation - i.c., its repetition upon a muscle which has been already divided-is attended with great disadvantages. In fact, by such a repetition of the tenotomy, anything like an approximative calcula. tion of the result is rendered impossible. In some cases the effect will be $n i l$, in others excessive.

This is probably owing to the cicatricial adhesions which are formed after the first operation, as they prevent the performance of the usual simple tenotomy. For, if we are not careful to divide these adhesions completely, it may easily occur that a small band, which has escaped our notice, will mar the effect; or if, in order to ensure their complete division, we have been obliged to incise the parts freely, a divergent squint (in division of the internal rectus) not unfrequently results, with considerable loss of mobility inwards, sinking of the carunculæ, exophthalmus, etc.; in short, all the disadvantages of the old and now abandoned operation. About nine years ago, I felt anxious to remedy, if possible, these defects by an alteration in the mode of operating; and $I$ then determined to investigate with greater accuracy; (I) the anatomical relations of the muscles, with regard to the capsule of Tenon, the sclerotic, conjunctiva, caruncle, etc.; and (2) the mechanical effect of the operation for strabismus.

\section{[To be continued.]}

\section{THE ETIOLOGY OF DIPHTHERIA.}

I IIAVE just read in this week's JoURNAL an article by Dr. Thursfield on the etiology of diphtheria, in which, while inclining to the opinion that there is a definite connection between it and local unsanitary conditions, he seems to consider that sufficient evidence has not been adduced by any writer on diphtheria to prove this conclusively. I beg to refer him to a paper by me in the Edinbursh Medical fournal for Feb. ruary 1860 , in which the causation of the disease is clearly traced to defective sanitary arrangements. In one house mentioned, typhoid fever attacked one of the inmates and proved fatal. Immediately afterwards, three children suffered from diphtheria, and were scarcely convalescent, when the mother and a servant girl were seized with typhoid fever. An abstract of the paper will be found in the Year Book of the New Sydenham Society for I 860 . Subsequent experience has amply confirmed the conclusions at which I then arrived. Very recently the subject has again been brought under my notice by Mr. Sleman, Medical Officer of Health for Tavistock. He has clearly traced the origin of an epidemic of the disease in Morwelham, an outlying hamlet in his district, to very defective sanitary arrangements.

$$
\text { R. W. CRICHTON, M.D., Tavistock. }
$$

\section{INFLUENCE OF MEAN TEMPERATURE ON THE PREVALENCE OF SMALL-POX.}

BY J. W. MOORE, M.D.Dubl.,

Diplomate in State Medicine and Ex scholar of Trinity College, Dublin ; Assistant Physician to Cork Street Fever Hospital, Dublin; etc.

Probably it would have been more correct to have headed this paper with the title, "Influence of Season on the Prevalence of Small-pox," but it will be conceded that temperature is the most important factor in the complex series of phenomena we denominate "season," and I wish to restrict myself on the present occasion to a consideration of its apparent influence on small-pox.

The subject is not a new one, for just one thousand years ago the Arabian physician, Rhazes, wrote to the following effect : "I am now to mention the seasons of the year in which the small-pox is most prevalent; which are, the latter end of the autumn, and the beginning of the sprins; and when in the summer there are great and frequent rains with continued south winds, and when the winter is warm, and the winds southerly." (A Treatise on the Small-pox and the Measles. By Rhazes. Translated from the original Arabic by William Alexander Greenhill, M.D., London : printed for the Sydenham Society, 1848. P. 33.) Avicenna also states that small-pox prevails most at the "turn of the year" (apud alterationem temporis), and especially in spring, the cases becoming numerous during a continuance of southerly winds (variolic multiplicantur in successione austrinorum, quando multiplicatur corum perflatio. Liber iv, tractatus 4, caput vi, De Variolis.)

Passing on to modern times, we find that of late years the relations between meteorology and disease have attracted the attention of many thoughtful writers upon medical and sanitary science. Among other writings on the subject, Dr. Ballard's able analysis of the Islington "Records of Sickness" (Eleventh Report of the Medical Officer of the Privy Council, 1868. No. 3), will always hold a foremost place. In that work he clearly traces the dependence of the prevalence of smallpox upon season. The latest contribution to our knowledge of this dependence of the disease on climatic influence is found in a paper (On the Seasonal Prevalence of some Eruptive Fevers in India) by: Dr. John Macpherson, late Inspector-General of Hospitals, which appeared in the Midtial Times and Gazette, for July 12th, 1873. The author quotes various passages from recent Sanitary Reports, to show that in India small-pox increases during the earlier months of the year, and reaches a maximum in May, simultaneously with the setting in of hot and dry weather towards the end of the N.E. monsoon. It then rapidly declines with the advent of the rains attending the $\mathrm{S}$. W. monsoon. Dr. Macpherson's remarks would go to prove that moist cool weather in India (that is, weather with a mean temperature of about 70 degs.) checks the spread and prevalence of small-pox. In fact, weather which closely resembles our northern and Atlantic summer, except that it is even hotter, is inimical to any great epidemic diffusion of the disease. Dr. Ballard, speaking of the result of twel-ye years observation in Islington, says (loc. cit., p. 73): "The rule has been for small-pox to prevail least in the summer, to increase through the autumn and winter, and to prevail most in the spring of the year. The smallest number of cases on the whole was observed in the months of September and October; the wave rose gradually through the succeeding months (with a slight check in February), to attain its highest point in the month of May. From this point it sank rapidly through July and August to attain its lowest point again in September. Small-pox is, therefore, clearly a disease the extension of which is promoted by cold weather and checked by hot weather."

These remarks would, at first sight, seem to be contradictory of Dr. Macpherson's statements as to the seasonal prevalence of small-pox in India. But, as I have already observed, the cool weather of India corresponds closely with our summer weather; and, as regards climatic influences, the absence or deficiency of moisture in the air, rather than the presence of very intense heat, would appear to be the chief determining cause of the greater prevalence of small-pox towards the close of the north east monsoon. Again, we may well imagine that defective vaccination among the millions of Hindoos and other natives, has told with terrible effect on the death-rate from small-pox; a death-rate which, there is every reason to believe, would be reduced to a minimum, owing to the warmth of the climate, were vaccination more generally carried out.

Dr. Ballard, in his paper, writes as follows: "The mean temperature of about 52 degs. is that which marks off the conditions, favourable or unfavourable, to the extension of small-pox. A temperature below th: 